\title{
PROTEÇÃO JURÍDICA DOS CONHECIMENTOS TRADICIONAIS PELO INSTITUTO DAS INDICAÇÕES GEOGRÁFICAS
}

\section{LEGAL PROTECTION OF TRADITIONAL KNOWLEDGE BY THE INSTITUTE OF GEOGRAPHICAL INDICATIONS}

\author{
${ }^{1}$ Karine de Souza \\ ${ }^{2}$ Liliana Locatelli
}

\section{RESUMO}

O estudo acerca da proteção jurídica dos conhecimentos tradicionais vem assumindo especial relevância, considerando a falta de um mecanismo legal que proteja esses saberes. Considerando a importância que tais conhecimentos possuem tanto sob o aspecto econômico, como também social e cultural, emerge a necessidade de regras que definam sua natureza jurídica, titularidade, possibilidade de exploração econômica, entre outros aspectos relevantes. A temática divide opiniões e tem sido objeto de estudo no âmbito das organizações internacionais, bem como em estudos (pesquisas) acadêmicos. Nesse contexto, este artigo buscou apontar os regimes de proteção jurídica que vêm sendo discutidos, analisando a possibilidade de proteção dos conhecimentos tradicionais pelo instituto das indicações geográficas. Observou-se que, apesar das similaridades, as regras aplicáveis às indicações geográficas não atendem a todas as peculiaridades e necessidades que devem ser atendidas na proteção jurídica dos conhecimentos tradicionais.

Palavras-chave: Conhecimentos tradicionais, Indicações geográficas, Proteção jurídica

\begin{abstract}
The study on the legal protection of traditional knowledge has taken on special relevance, considering the lack of a legal mechanism to protect this knowledge. Considering the importance not only economical, but also social and cultural of such knowledge emerges the need for rules defining its legal status, ownership, possibility of economic exploitation, among other relevant aspects. The issue divides opinions and has been studied within the scope of international organizations, as well as academic studies (research). In this context, this paper aims to point out the legal protection schemes that are being discussed, analyzing the possibility of protection for traditional knowledge by the Institute of geographical indications. It was observed that, despite the similarities, the rules applied to geographical indications do not meet all the peculiarities and needs recquired to the legal protection of traditional knowledge
\end{abstract}

Keywords: Geographical indications, Legal protection, Traditional knowledge

\footnotetext{
${ }^{1}$ Mestre em Direito pela Universidade Regional Integrada do Alto Uruguai e das Missões - URI, Erechim, Rio Grande do Sul, Campus Santo Ângelo, (Brasil). Advogada Mediadora, e Professora do Curso de Direito da Faculdade Santa Amélia - SECAL, Ponta Grossa, Paraná. E-mail: karinesouzafw @ yahoo.com.br ${ }^{2}$ Doutora em Direito pela Universidade Federal de Santa Catarina - UFSC, Florianópolis, (Brasil). Professora Colaboradora da Graduação e Pós-Graduação em Direito da URI/FW, na áreas de Direito do Consumidor, Direito Civil e Propriedade Intelectual. E-mail: lilianalocatelli00@yahoo.com.br
} 


\section{INTRODUÇÃO}

As comunidades tradicionais, que possuem características intrínsecas em sua relação de respeito e convivência com o meio ambiente, como as indígenas, quilombolas, seringueiros, caiçaras, quebradeiras de coco, pescadores artesanais, babaçueiros, entre outros, guardam valiosos saberes, inclusive de manipulação de espécies do bioma que os cercam.

Considerando diversas tentativas de conceituar esses saberes infere-se que conhecimento tradicional - CT, pode ser definido como sendo a expressão usada para designar os saberes das comunidades tradicionais indígenas e não indígenas, elaborados através da experiência prática destas comunidades, a partir da relação humanos/natureza, normalmente permeado por questões místicas ou espirituais e que são repassados oralmente ao longo das gerações.

Esses conhecimentos incluem desde aplicação científica, comercial ou industrial, como medicamentos e cosméticos, como também expressões culturais danças, cantos, pinturas, estórias, entre outras.

Tendo em vista a importância que tais conhecimentos possuem tanto sob o aspecto econômico, como também social e cultural emerge a necessidade de uma proteção jurídica que estabeleça parâmetros adequados que vão desde a definição legal desses saberes, até a titularidade, a proteção dos direitos daí decorrentes e a necessidade de mecanismos que coíbam a utilização indevida por terceiros desses conhecimentos e dos ativos correspondentes.

Nesse intuito, organismos internacionais como a Organização Mundial da Propriedade Intelectual (OMPI), a Organização Mundial do Comércio (OMC) e a Organização das Nações Unidas (ONU), têm estabelecidos debates em torno da necessidade de proteção dos conhecimentos tradicionais, especialmente os associados, CTAs, que são aqueles relacionados ao manejo e aplicação dos recursos da biodiversidade.

Apesar das diversas tratativas, ainda não há consenso em relação ao instrumento jurídico ideal para proteger esses saberes, tampouco sobre a própria conceituação de conhecimentos tradicionais. Enquanto a OMC defende a proteção através do instituto das patentes - apesar de questionável especialmente pela ausência de alguns requisitos típicos do referido instituto, como a novidade, por exemplo, a OMPI tem se inclinado para criação de um regime de proteção sui generis específico para esses conhecimentos. Por outro, lado se cogita também a possibilidade de proteção desses conhecimentos pelo instituto da indicação geográfica, considerando que este apresentaria algumas similaridades com o modelo sui generis discutido. 
O presente estudo visa, assim, apontar as possibilidades de proteção jurídica aos conhecimentos tradicionais, associados ou não, consoante as discussões nos organismos internacionais e na bibliografia especializada, analisando a pertinência ou não da proteção desses saberes e das inovações dele decorrentes pelo instituto da indicação geográfica.

Para realização do presente trabalho, a metodologia adotada contemplou o método dedutivo, partindo-se do estudo de teorias de base já estabelecidas com o intuito de responder ao objeto da pesquisa. O procedimento foi bibliográfico e a técnica de pesquisa utilizada a indireta, com consulta a materiais gráficos.

\title{
2. CONHECIMENTOS TRADICIONAIS: UM CONCEITO EM CONSTRUÇÃO
}

O termo "conhecimentos tradicionais" enquanto categoria para designar os saberes produzidos pelas populações tradicionais e indígenas tem sua origem relacionada a discussões políticas internacionais. De acordo com Rodriguez, é possível afirmar que o desenvolvimento do termo passou a se organizar a partir de duas frentes: discussões sobre direito do autor, surgidas na década de 70 e debates internacionais sobre a natureza (RODRIGUEZ, 2011).

Ainda, conforme o referido autor:

\begin{abstract}
A primeira frente surge de uma preocupação trazida à tona durante a Conferência de Estocolmo (1967), para com as obras não publicadas e com aquelas em que o autor não poderia ser individualmente identificado. É nesse registro que a tradição popular passa a ser inicialmente debatida em âmbito internacional, sob a rubrica do termo folclore. As características de oralidade e de pertencimento a um grupo ou comunidade foram entendidas como fragilidades desses saberes, justificando a proteção dessas expressões culturais. A segunda frente conta com o papel ativo dos povos indígenas e dos movimentos sociais ambientalistas que, ao discutirem alternativas de desenvolvimento e começarem a acompanhar as reuniões da ONU na década de 1980, abriram espaço para tratar dos conhecimentos dos povos tradicionais relacionados à proteção da biodiversidade (RODRIGUEZ, 2011, p. 48).
\end{abstract}

É possível afirmar que esses debates partilham de algumas questões comuns em relação à proteção desses saberes - apesar de as alternativas apresentadas serem dissonantes: como proteger o produto da cultura, sem proteção aos portadores da tradição? Como proteger os portadores, se há dificuldade de identificação, uma vez que o saber é coletivo? E, por fim, como conciliar exploração comercial e capacidade criativa? (ZANIRATO, RIBEIRO, 2007).

Acerca da conceituação de conhecimentos tradicionais não há consenso na doutrina especializada, tampouco nas definições trazidas pelos organismos internacionais ou organizações não governamentais. Contudo, conforme explica Kiewelo, existem algumas características comuns a todas definições, quais sejam: 


\begin{abstract}
Ideais e pressupostos relativos a um conhecimento interno, diferente do conhecimento da sociedade circundante, centrado na localidade em que é utilizado e abarcando o conhecimento exógeno introduzindo na comunidade ao longo de determinado período; Informação sistemática, mas que se mantém na informalidade, na oralidade; Conjunto de todos os saberes e práticas, implícitas e explícitas aplicados na vida socioeconômica e ecológica. Conjunto de experiências e conhecimento de um grupo étnico, base para decisões no âmbito de conflitos familiares, criados de forma endógena, com elementos externos, mas que são integrados internamente, por meio de capacidade intrínseca de absorção de conhecimentos relevantes; Conhecimento local, tradicional e único, desenvolvido em razão de condicões específicas de uma dada comunidade numa dada área geográfica (KIEWELO, 2009, p. 160). (grifos nossos)
\end{abstract}

Para Leutzinger conhecimentos tradicionais corresponde aos "saberes que possuem as populações tradicionais, sendo gerados de forma coletiva e ao longo do tempo e consolidados em virtude da experiência e de uma estreita relação com o meio natural”. (LEUTZINGER, 2009, p. 230)

Os conhecimentos tradicionais, portanto, nascem no seio das comunidades tradicionais e indígenas, fruto da interação do homem com o meio natural, operando com lógicas perceptuais e sensíveis e estabelecendo uma relação não utilitarista, mas de simbiose. Para essas sociedades há uma interligação orgânica entre o mundo natural, sobrenatural e a organização social.

Esses saberes englobam um conjunto de procedimentos de aprendizagem e de divisão de conhecimentos, um acervo de práticas e processos que vão dando sustentação à vida das pessoas e dos grupos que os foram criando.

Para Soares:

Os conhecimentos tradicionais são os saberes e técnicas que os índios e outras comunidades locais (tais como os quilombolas, os caiçaras, os seringueiros, os pescadores, os ribeirinhos, entre outras) têm e utilizam para sua sobrevivência e para o atendimento de necessidades culturais, espirituais, materiais e financeiras das presentes e futuras gerações. São conhecimentos sobre as potencialidades dos recursos naturais e sobre formas e técnicas de manejo e sua gestão, bem como sobre métodos de caça, pesca, processamento de alimentos e propriedades fitoterápicas de elementos da flora (SOARES, 2009, p. 195).

A definição trazida pela Organização Mundial de Propriedade Intelectual - OMPI, consagra a expressão "conhecimentos tradicionais" em duplo sentido: lato sensu, quando diz respeito à criação, às inovações e às expressões culturais resultantes da atividade intelectual no campo industrial, científico, literário, transmitidos de geração em geração, e que considerados como pertencentes a um determinado povo ou ao seu território; e stricto sensu, alcançando apenas os conhecimentos de manejo agrícola, ambiental e medicinal. Nesse caso, 
são excluídas do conhecimento tradicional as músicas, os cantos, as narrativas, que são abrigados pela categoria expressões do folclore (OMPI. WIPO/GRTKF/IC/5/8, 2003, itens 67/70).

No Relatório da Oitava Reunião do Grupo de Trabalho Especial de Composição aberta sobre o artigo $8^{\circ}$, alínea J e disposições conexas da Convenção sobre a Diversidade Biológica tratado da Organização Nacional das Nações Unidas - ONU, a definição trazida para o termo conhecimento tradicional é de que este, engloba o conhecimento, inovação e práticas das comunidades indígenas e locais com um estilo de vida tradicionais voltados à conservação e utilização sustentável da diversidade biológica. Desenvolve-se a partir da experiência adquirida ao longo dos anos e adaptado à cultura local e meio ambiente, sendo gerados e transmitidos oralmente através das gerações (SCBD, UNEP/CBD/WG8J/5/6, §47; CDB, artigo $8^{\circ}$ ).

Os saberes das populações tradicionais "designam os múltiplos conhecimentos, práticas, técnicas e tecnologia dos povos ou comunidades tradicionais, não se limitando àqueles de natureza prática, associados à sua sobrevivência ou alimentação" (RODRIGUES JUNIOR, 2010, p. 40).

Certo, contudo, é que os conhecimentos tradicionais associados à biodiversidade, aqueles de natureza prática, técnica, acerca da manipulação, aplicação medicinal e alimentar, de espécies vegetais e animais, que permite o manejo dos recursos natural respeitado a capacidade de recuperação das espécies animais e vegetais, convergindo na manutenção do bioma e uso sustentado dos ecossistemas naturais (DIEGUES; ARRUDA, 2001), ganhou maior ênfase, devido as suas potencialidades para alimentar as indústrias dos setores de engenharia química, agrícola, alimentar e farmacológica.

$\mathrm{O}$ conhecimento tradicional associado à biodiversidade tem sido visto como uma ferramenta para encurtar etapas de pesquisas, estreitando o foco de estudo para umas plantas ou técnicas agrícolas cujos efeitos já sejam parcialmente conhecidos, reduzindo custos e aumentando as chances de gerar um produto passível de comercialização (RODRIGUEZ, 2010).

Contudo, imperioso mencionar que, os saberes das populações tradicionais, ao contrário do saber formal, científico, não são isolados do aspecto espiritual e produção coletiva, sendo sua construção cultural. "Para muitas comunidades locais ou tradicionais, a vida é representada por uma rede de ligações entre o homem, a natureza e a espiritualidade" (RODRIGUES JUNIOR, 2010, p. 41). 
Esses conhecimentos não raras vezes são ensinados através de histórias, canções, folclore, crenças, rituais, normas e claro, práticas. São partilhados entre o grupo e sua propriedade tende a ser coletiva e, juntamente com os recursos biológicos, constituem uma extensão da vida social desses grupos. A natureza é vista como sagrada, devendo-se extrair dela apenas o indispensável para o atendimento das necessidades do grupo e muitas práticas somente tomam significado quando associadas a questões místicas.

Nesse sentido:

[...] relacionar o conhecimento tradicional unicamente à biodiversidade significa menosprezar a importância do fator humano na construção do conhecimento tradicional, deixando de lado a construção cultural do saber.Dessa forma, o conhecimento tradicional das rendeiras da Ilha de Santa Catarina (Florianópolis-SC), ou as paneleiras de Goiabeiras (Espírito Santo), por exemplo, não estaria sendo abrangido pelo conceito legal de conhecimento tradicional utilizado no Brasil. (FÁVERO, 2010, p. 47)

Acerca do conceito de populações tradicionais, importante referir que na doutrina, "comunidade", "população", "sociedade" tradicional são termos que frequentemente são usados como sinônimos, para designar um grupo de pessoas, culturalmente diferenciadas que compartilham costumes e práticas diferenciados em relação àqueles que habitam regiões centrais e industrializadas, chamadas metrópoles. "São minorias étnicas que cultivam uma interação direta com a natureza. Estes grupos possuem culturas, normas consuetudinárias e características que as diferenciam da população urbana"(RODRIGUES JUNIOR, 2010, p.28).

Para Diegues e Arruda, populações ou sociedades tradicionais são:

[...] grupos humanos diferenciados sob o ponto de vista cultural, que reproduzem historicamente seu modo de vida, de forma mais ou menos isolada, com base na cooperação social e relações próprias com a natureza. Tal noção refere-se tanto a povos indígenas quanto a segmentos da população nacional, que desenvolveram modos particulares de existência, adaptados a nichos ecológicos específicos (DIEGUES; ARRUDA, 2001, p. 22).

De acordo com Juliana Santilli, essas populações apresentam como forte característica "a intenção de manter-se no território que exploram, dotando-se de controle sobre o mesmo, preservando o ambiente de forma equilibrada e o desejo de manter seus traços culturais, reafirmando-os e reelaborando-os” (SANTILLI, 2005, p. 120).

É inegável que as discussões sobre a proteção dos conhecimentos tradicionais têm implicações diretas em mais de uma área estratégica: do uso sustentável e manejo da biodiversidade, passando pela proteção a diversidade cultural, questões de direitos humanos, 
distribuição de riquezas, ética e pesquisa científica até chegar a questões de comércio internacional e, por isso, é tão necessária.

Contudo, ainda não resta delimitado, conforme já dito, um conceito de conhecimento tradicional que seja aceito de forma unânime pelos organismos internacionais e, sem definir o objeto de proteção inexiste ainda, uma solução acerca do melhor meio de se proteger e promover os conhecimentos tradicionais.

O tópico seguinte dedica-se a apresentação dos principais desdobramentos e avanços acerca da forma de proteção jurídica adequada a esses conhecimentos.

\section{AS DISCUSSÕES E PROPOSTAS ACERCA DA PROTEÇÃO JURÍDICA DOS CONHECIMENTOS TRADICIONAIS}

No âmbito das negociações multilaterais as discussões acerca da proteção dos conhecimentos tradicionais associados, se apresentam de forma distinta e até, aparentemente, antagônicas. As sugestões incluem a proteção como Patrimônio Cultural Imaterial; a aplicação do sistema de proteção à propriedade industrial das patentes; até a criação de um regime sui generis específico para proteção desses saberes, com vistas ao resguardo do caráter cultural dos conhecimentos tradicionais, bem como da exploração econômica ponderada e sustentável.

Cronologicamente falando, as discussões internacionais acerca dos conhecimentos tradicionais têm início na década de 60, com uma preocupação da Organização das Nações Unidas para Educação, Ciência e Cultura - UNESCO, em relação à proteção legal das expressões folclóricas, intimamente ligadas a manifestações culturais dos povos e comunidades indígenas e tradicionais, seus desenhos, textos e artesanato.

Como resultados deste processo, a UNESCO e a OMPI, em 1985, desenvolveram Disposições para Modelos de Leis Nacionais com o intuito de proteger essas manifestações intelectuais. Recentemente, em 2003, a UNESCO aprovou a Salvaguarda do Patrimônio Cultural Imaterial, que tem por objetivos a salvaguarda, respeito e sensibilização sobre o patrimônio cultural imaterial, que inclui, entre outros, o conhecimento e seus usos relacionados ou não à natureza. (UNESCO, Convenção para a Salvaguarda do Patrimônio Cultural Imaterial, 2003)

Também na década de 80, algumas agências de conservação e preservação não tardaram em considerar o conhecimento ecológico das populações com estilos de vida tradicionais como uma valiosa matriz de tecnologias a serem exploradas e potencializadas na 
busca por vias sustentáveis de desenvolvimento e na preservação da biodiversidade (KARAM, 2008).

$\mathrm{Na}$ década de 90, durante a Conferência da ONU sobre Meio Ambiente e Desenvolvimento (CNUMAD), realizada no Rio de Janeiro no ano de 1992, que ficou mais conhecida como ECO92, assinou-se o tratado da Convenção da Biodiversidade Biológica $(\mathrm{CDB})$, um dos mais relevantes tratados internacionais relacionados ao meio ambiente e que possui três bases principais - a conservação da diversidade biológica, o uso sustentável da biodiversidade e a repartição justa e equitativa dos benefícios provenientes da utilização dos recursos genéticos (Convenção sobre Diversidade Biológica CDB, Decreto Legislativo $\mathrm{n}^{\mathbf{0}} 2$, de 1994).

De acordo com Muller:

\begin{abstract}
O tratado reconhece a importância social, cultural, ecológica e ambiental dos conhecimentos tradicionais, bem como estabelece que estes conhecimentos tradicionais (em nível de conhecimentos, inovações e práticas) devam ser promovidos, desenvolvidos e mantidos com a participação e consentimento prévio das comunidades tradicionais (MULLER, 2006, p. 52-53).
\end{abstract}

O protocolo da CDB visa à introdução um regime internacional de proteção - com regras próprias e específicas, que seja competente para disciplinar o acesso e o uso dos recursos da biodiversidade tutelados pela CBD e dos conhecimentos tradicionais associados (regime internacional ou RI). Deveria ter sido concluído em 2010, mas permanece com pontos relevantes em aberto, em virtude da falta de consenso dos negociadores envolvidos. (RODRIGUES JUNIOR, 2010)

Apesar disso, os elementos centrais do futuro regime internacional já estão indicados de maneira clara. O primeiro elemento diz respeito à matéria de proteção. O Grupo de Trabalho sobre o art. 8(j) e dispositivos conexos da Convenção da Diversidade Biológica recomenda a todos os envolvidos na negociação do regime internacional a inclusão em seu escopo de todos os conhecimentos tradicionais associados, inclusive aqueles publicamente acessíveis, desde que vinculados culturalmente a alguma comunidade tradicional. (SCBD, $\mathrm{UNEP} / \mathrm{CBD} / \mathrm{WG} 8 \mathrm{~J} / 5 / 6, \S 47$; CDB, artigo $8^{\circ}$ ).

Ainda de acordo com o modelo proposto, não há necessidade de haver registro/anotação prévia que comprove a existência do conhecimento tradicional. Para serem elegíveis para proteção é ser conservados por comunidades tradicionais. (RODRIGUES JUNIOR, 2010). 
Em relação à titularidade sobre os direitos de propriedade dos conhecimentos tradicionais associados, estes seriam das comunidades tradicionais - sendo assim, direitos de titularidade coletiva Em relação ao acesso, esse estaria condicionado à obtenção do consentimento Prévio Livremente Informado a todos os múltiplos codetentores ou à obtenção do consentimento de apenas de um dos grupos. As comunidades usufruiriam das típicas prerrogativas conferidas por direitos de propriedade, gozando do direito de transferir e licenciar seus conhecimentos tradicionais associados; se opor a qualquer tipo de reprodução, utilização ou exploração não autorizada de seus conhecimentos tradicionais associados; do direito de transmitir conhecimentos às gerações futuras das comunidades; de controlar as diversas aplicações de seus conhecimentos tradicionais, ou seja, caso um usuário pretenda aplicar o conhecimento tradicional associado licenciado para fim diverso do previsto, terá de negociar um novo acordo; do direito de receber benefícios pelo uso de seus conhecimentos; e do direito de revogar o acordo de acesso e repartição de benefícios quando terceiros infringirem seus termos. Importante sublinhar que os direitos conferidos às comunidades tradicionais se estendem a conhecimentos tradicionais para fins científicos não comerciais e para a realização de inventários que objetivem conservá-los para as gerações futuras (SCBD, UNEP/CBD/WG8J/5/6, §19 e SCBD, UNEP/CBD/WGABS/CRP.1 §19).

A título complementar, observa-se que no Brasil, atualmente, a Lei $\mathrm{n}^{\circ} 13.123$ de 2015 regulamentando o inciso II do $\S 1^{\circ}$ e o $\S 4^{\circ}$ do art. 225 da Constituição Federal de 1988, bem como o artigo $1^{\text {o}}$; alínea 'j' do Artigo $8^{\circ}$; alínea 'c' do artigo 10; artigo 15 e os $\S \S 3^{\circ}$ e $4^{\circ}$ do artigo 16 da Convenção sobre Diversidade Biológica - tratado em que o Brasil é signatário, passou a dispor sobre o acesso ao patrimônio genético, a proteção e o acesso ao conhecimento tradicional associado e a repartição de benefícios para conservação e uso sustentável da biodiversidade. (BRASIL, 2015)

A Lei N. 13.123/2015 incorpora parte do projeto de regime de proteção proposto pela $\mathrm{CDB}$, incluindo a repartição justa e equitativa de benefícios decorrentes de exploração econômica e o condicionamento do acesso ao patrimônio genético à obtenção do consentimento prévio informado. Dispõe em seu artigo $8^{\circ}$ que os conhecimentos tradicionais conhecimentos tradicionais associados ao patrimônio genético de populações indígenas, de comunidade tradicional ou de agricultor tradicional ficam protegidos contra a utilização e exploração ilícita. E, no parágrafo $3^{\circ}$ do artigo $8^{\circ}$ afirma que o conhecimento tradicional associado ao patrimônio genético de que trata esta Lei integra o patrimônio cultural brasileiro e poderá ser depositado em banco de dados, conforme dispuser o Conselho Gestão do 
Patrimônio Genético (CGen) ou legislação específica.. (BRASIL, Lei n. 13.123/2015, arts. $8^{\circ}$ e $\left.9^{\circ}\right)$

Apesar de determinar que os CTAs integram o patrimônio cultural brasileiro, a Lei $\mathrm{n}$. 13.123/2015 dispõe que o acesso ao patrimônio genético ou ao conhecimento tradicional associado será efetuado sem prejuízo dos direitos de propriedade material ou imaterial que incidam sobre o patrimônio genético ou sobre o conhecimento tradicional associado acessado ou sobre o local de sua ocorrência.

É possível afirmar que a Lei n. 13.123/2015 cria um regime de proteção sui generis para os conhecimentos tradicionais associados à biodiversidade ao proteger o instituto enquanto patrimônio cultural imaterial, reconhecer direitos coletivos de exploração econômica sobre estes - ainda que discutível se é justa a repartição e condicionar o acesso.

No contexto da Organização Mundial do Comércio (OMC), o Acordo sobre Aspectos dos Direitos de Propriedade Intelectual Relacionados ao Comércio- TRIPS (sigla em inglês) que visa regulamentar a propriedade intelectual no contexto dessa organização e das relações comerciais internacionais, não faz qualquer menção à em relação à proteção jurídica dos conhecimentos tradicionais.

Não obstante essa lacuna, o TRIPS ampliou o leque dos direitos de propriedade industrial relacionados a patentes de invenção através da chamada "cláusula da biotecnologia" cristalizada em seu art. 27(3)(b), mas continua omisso acerca dos CTs. Essa cláusula permite que proteja através de patentes os microrganismos e processos essencialmente biológicos para a produção de plantas ou animais e variedades vegetais, quando pedido de patente atenda aos requisitos de novidade, atividade inventiva e aplicação industrial. (OMC. TRIPS, 1996, art. 27 caput e 27, (3) (b) ).

O TRIPS, no mesmo dispositivo, flexibiliza a proteção de organismos vivos deixando a critério dos Estados membros, a opção ou não pela proteção e a forma de protegêlos, senão vejamos:

b) plantas e animais, exceto microorganismos e processos essencialmente biológicos para a produção de plantas ou animais, excetuando-seos processosnãobiológicose microbiológicos. Não obstante, os Membros concederão proteção a variedades vegetais, seja por meio de patentes, seja por meio de um sistema "sui generis" eficaz, seja por uma combinação de ambos. (OMC. TRIPS, 1996, 27, (3) (b) ).

Há, na redação uma limitação para o patenteamento de partes de seres vivos em si, contudo, não resta dúvida em relação a proteção do processo de isolamento de determinado 
material genético obtido por meio de intervenção humana, afinal há atividade inventiva ainda que no processo de isolamento de determinada característica genética da planta ou animal.

Mas, conforme mencionado acima, o TRIPS é omisso em relação à proteção dos conhecimentos tradicionais - associados ou não à biodiversidade. Somente em 2001, durante a rodada de negociações em Doha, houve a inclusão da temática entre os tópicos a ser abordados nos debates da então negociação. Nesse sentido, ficou estabelecido no parágrafo 19 da Declaração de Doha que o Conselho TRIPS deveria analisar, entre outras, a relação entre o Acordo TRIPS e a Convenção sobre a Diversidade Biológica, a proteção do conhecimento tradicional e folclore, e outros novos desenvolvimentos relevantes levantadas pelos membros de acordo. (Declaricion Doha, 2001, parágrafo 19)

Apesar disso, as lacunas permanecem e as recentes discussões junto à $\mathrm{OMC}$ tem demonstrado inclinação da organização para uma proteção meramente defensiva concedendo direitos de exclusividade em favor de instituição privadas e impedindo a exploração por terceiros indevidos. Não há, por enquanto, proteção aos direitos dos provedores desses recursos, nem menção de repartição de benefícios econômicos resultantes do uso comercial de recursos biológicos quando associados aos conhecimentos de comunidades tradicionais.

Acerca dos debates na Organização Mundial de Propriedade Intelectual (OMPI), é possível afirmar que estes se iniciaram ao final dos anos 90. Entre 2001 e início de 2010, o Comitê Intergovernamental sobre Propriedade Intelectual, Recursos Genéticos, Conhecimentos Tradicionais e Folclore - CIG reuniu-se quinze vezes para redigir um projeto de disposições para a proteção dos conhecimentos tradicionais, apto a servir de base a um futuro acordo internacional para a matéria.

Para a OMPI, quaisquer formas de conhecimentos tradicionais resultantes de atividades intelectuais, conduzidas na esfera de comunidades culturais, independentemente das áreas técnicas a que se vinculam seriam elegíveis para proteção pelo Regime Internacional de Proteção proposto pela OMPI. Logo, no projeto da Organização Mundial de Propriedade Intelectual, a tutela oferecida não se limita aos conhecimentos tradicionais associados à biodiversidade.

Nesse sentido, para receber a proteção legal os conhecimentos tradicionais precisam, no mínimo, preencher os seguintes requisitos: terem sido criados e constituídos em contextos tradicionais e transmitidos de geração a geração; estarem vinculados ou ser reconhecidos como pertencentes a uma comunidade tradicional ou povo, que os preserva e transmite de geração a geração; ou ainda estarem vinculados à identidade cultural de uma comunidade 
tradicional ou de um povo, dado que algum destes grupos seja reconhecido como seu titular, uma vez que exerce custódia, conservação, titularidade coletiva ou responsabilidade cultural sobre eles (WIPO, Revised provisions for the protection of traditional knowledge, 2010, $\operatorname{artigo} 4^{\circ}$ (i), (ii) e (iii)).

A proposta da OMPI caminha para criação de um regime sui generis de proteção aos conhecimentos tradicionais, estabelecendo uma proteção no sentido defensivo - com vistas a criação de estratégias que visem assegurar que terceiros não recebam direitos de propriedade intelectual ilegítimos sobre os conhecimentos tradicionais, incluindo a possiblidade de alteração dos sistemas de patentes administrados pela OMPI.- e proteção positiva - buscando impedir a utilização não autorizada por terceiros e exploração ativa dos conhecimentos tradicionais pela própria comunidade de origem. (WIPO, Traditional Knowledge, 2015)

Em relação à matéria elegível de proteção, o projeto da OMPI é mais restritivo do que da CCDB. No projeto da OMPI os conhecimentos tradicionais publicamente acessíveis (os chamados conhecimentos tradicionais em "domínio público") são elegíveis para proteção, desde que preencham as três condições de proteção referidas acima. Em relação à formalidade para obtenção da proteção, o projeto da OMPI não condiciona a proteção dos conhecimentos tradicionais ao cumprimento de qualquer formalidade, mas oferece aos Estados a discricionariedade para estabelecer registros, a fim de assegurar transparência, segurança e conservar os Conhecimentos tradicionais, ou como condição para que as comunidades obtenham proteção legal (WIPO, Revised provisions for the protection of traditional knowledge, 2010, artigo 11).

Acerca da titularidade, esta seria coletiva, pertencendo a todas as comunidades tradicionais que conservam ou desenvolvem as categorias de conhecimentos tradicionais mencionadas acima, e, na hipótese de duas ou mais comunidades compartilharem um mesmo CT elegível para proteção legal, todas elas teriam direitos sobre estes (WIPO, 2010, p. 71 e 88; WIPO, WIPO/GRTKF/IC/16/5, artigo $4^{\circ}$ ).

Em relação aos direitos conferidos, o art. $2^{\circ}$ do projeto da OMPI assinala que os Estados gozam de ampla liberdade para elegerem os mecanismos legais que julgarem mais adequados para a proteção dos conhecimentos tradicionais contra atos de apropriação indébita e usos culturalmente desrespeitosos, podendo, protegê-los, inter alia, mediante normas de concorrência desleal, direitos de propriedade e um regime de responsabilidade. (WIPO, Revised provisions for the protection of traditional knowledge, artigo $2^{\circ}, 2010$ ).

Uma das disposições substantivas do projeto determina que os Estados nacionais reconheçam às comunidades tradicionais o direito de condicionar todo e qualquer acesso aos 
seus conhecimentos tradicionais à obtenção de seu Consentimento Prévio Livre Informado ou a uma autorização, concedida por uma organização, investida pelas comunidades tradicionais titulares de direitos nesta competência. Essa afirmação equivale a reconhecer-lhes um direito de propriedade sobre seus conhecimentos tradicionais (WIPO, Revised provisions for the protection of traditional knowledge, anexo 4, 2010).

Ante o explanado, as alternativas de proteção jurídica até então apresentadas no contexto internacional, portanto, podem ser resumidas da seguinte forma: “1)regime de Propriedade Intelectual convencional; 2) Regime sui generis de Propriedade Intelectual e 3) Regime sui generis distinto.” (TEIXEIRA MAZAUDOX, 2006, p.335/336).

\section{A PROTEÇÃO DOS CONHECIMENTOS TRADICIONAIS PELO INSTITUTO DA INDICAÇÃ̃O GEOGRÁFICA}

As indicações geográficas são signos distintivos que gozam de proteção e natureza jurídica distinta dos demais institutos da propriedade industrial, como as marcas e as patentes. Consoante essas diferenças e a natureza jurídica peculiar desse signo geográfico, há argumentos favoráveis à proteção dos conhecimentos tradicionais por meio desse instituto. Fávero (2010) aponta que muitos dos aspectos abordados na discussão acerca da criação de um sistema sui generis de proteção jurídica dos conhecimentos tradicionais estão inseridos na forma de proteção das indicações geográficas, o que corrobora com a utilização desse mecanismo para proteger tais saberes.

As indicações geográficas possuem definição pelo TRIPs, o qual determina que para configurar esse instituto há que se ter presente (nos produtos) uma reputação, qualidade ou característica vinculada ao meio geográfico de origem. (OMC. TRIPs, art. 22)

Nos termos da legislação brasileira, a indicação geográfica se divide em duas espécies: indicação de procedência (IP) e denominação de origem (DO). Enquanto a IP se restringe ao meio geográfico de produção/prestação, extração ou fabricação que se tornou reconhecido, a DO exige qualidades ou características do produto/serviço vinculadas a esse meio, decorrentes de fatores naturais e humanos. E o que se protege (registra) em ambos os casos é o nome geográfico. (BRASIL, Lei n. 9.279/1996, art. 177)

Denota-se que em quaisquer dos regulamentos analisados, o fator preponderante é o vínculo com o meio geográfico de origem. Os conhecimentos tradicionais, não obstante seja importante o vínculo com o meio natural, nem sempre estão relacionados à um (único) meio geográfico determinado. Para isso, FÁVERO (2010) argumenta que nada impede que existam 
mais de uma IG para o mesmo produto ou serviço, ou seja, mais de um local (meio geográfico de origem) protegido.

Parece, entretanto, que a questão em se tratando de conhecimentos tradicionais transcende o meio geográfico de origem e ainda que se possam delimitar várias regiões, por vezes, o saber fazer que caracteriza esse conhecimento não é passível de delimitação geográfica, eis que perpassado para várias gerações que não mantém necessariamente um vínculo com uma ou mais localidades determináveis.

Outra questão, apontada como uma similaridade entre os dois institutos, é a titularidade. Ao contrário dos demais institutos da propriedade industrial, nas indicações geográficas a titularidade é coletiva, ou seja, de todos os produtores ou prestadores estabelecidos na área geográfica demarcada. (BRASIL, Lei n. 9.279/1996, art. 182) Para fins de registro, por sua vez, se exige como substituto processual uma pessoa jurídica que represente a coletividade (INPI, IN n. 25/2013).

As indicações geográficas permitem apenas excepcionalmente uma titularidade individual, no caso em que o produtor/prestador seja o único na área geográfica demarcada a explorar a atividade característica da IG. (INPI, IN n. 25/2013). Considerando todos essas peculiaridades que envolvem a titularidade da indicação geográfica, parece que esse aspecto legal se coaduna com a natureza dos conhecimentos tradicionais. No entanto, uma questão merece ser observada, qual seja o fato de que ainda que a indicação conte com titularidade, em regra, coletiva, seus titulares necessariamente precisam ter um vínculo com o meio geográfico de origem dos produtos/serviços, eis que o estabelecimento nesse local é requisito para o uso da indicação, nos termos da lei brasileira. (Brasil, Lei n. 9.279/1996, art. 182) E, diante disso, como regulamentar os ativos decorrentes dos conhecimentos tradicionais, como medicamentos, que podem(riam) ser explorados por terceiros?

Daqui emerge outra discussão, qual seja da inalienabilidade e imprescritibilidade. Da proteção conferida às indicações geográficas no Brasil infere-se a existência de tais limites/ prerrogativas ao uso do signo geográfico. Da mesma forma, são aspectos que devem ser resguardados nos conhecimentos tradicionais. A questão mais complexa é a possibilidade de "licenciar" o uso desses conhecimentos, o que importa, por exemplo, aos ativos decorrentes dos conhecimentos tradicionais associados, mas não se coaduna com a natureza das indicações geográficas. (LOCATELLI, 2007)

FAVERO (2010) ressalta ainda outra característica das indicações geográficas, qual seja o fato de que no Brasil o seu registro é declaratório. De fato esse aspecto é pertinente aos 
conhecimentos tradicionais, em que pese em alguns países europeus, por exemplo, esse registro seja constitutivo.

Ademais, em algumas legislações como da União Europeia, no caso da Indicação Geográfica Protegida, exige-se que pelo menos uma das fases de produção, transformação ou elaboração se deem na área geográfica demarcada, sendo que no caso da Denominação de Origem as três fases devem ocorrer nessa área. Isso traria alguns limites injustificados à exploração, por exemplo, de alguns produtos derivados de conhecimentos tradicionais associados.

Por fim, no contexto da legislação brasileira não existe uma proteção positiva efetiva às indicações geográficas, sendo que a Lei n. 9.279/1996 prioriza a proteção negativa, sendo essa ainda bastante limitada à vedação de falsa origem, o que não atende às necessidades dos conhecimentos tradicionais e dos ativos deles resultantes.

Não obstante existam similaridades entre os institutos, há ainda algumas peculiaridades dos conhecimentos tradicionais que não recomendam a utilização das indicações geográficas como um instrumento de proteção jurídica efetiva a esses saberes e os ativos deles decorrentes, especialmente nos termos da legislação brasileira.

\section{CONSIDERAÇÕES FINAIS}

É inegável a necessidade de um regime jurídico que proteja de forma efetiva os direitos dos titulares dos conhecimentos tradicionais. No entanto, a natureza complexa desses saberes e dos ativos deles resultantes faz com que se tenha uma maior dificuldade de elaborar regras adequadas.

Nesse contexto, emergem discussões nas organizações internacionais que esbarram nos diferentes regimes jurídicos de cada país, bem como nos objetivos diversos que norteiam tais organismos.

Importa, assim, identificar nas diversas propostas de proteção jurídica desses conhecimentos, as fragilidades e possibilidades. A utilização das patentes, por exemplo, como mecanismo de proteção jurídica aplicável aos conhecimentos tradicionais não atende a todas as peculiaridades desse instituto. Por outro lado, o sistema sui generis parece não ter atingido a maturidade necessária para responder a todos os interesses envolvidos.

$\mathrm{Na}$ tentativa de utilizar do sistema de propriedade industrial vigente para proteger os conhecimentos tradicionais, surge a possibilidade de utilização das indicações geográficas 
para esse fim. Similaridades entre os dois institutos existem, tais como a titularidade coletiva, o vínculo com o meio natural e a ausência de limite para a proteção (imprescritibilidade).

Não obstante tais semelhanças ou elos, o objeto precípuo tutelado - vínculo com o meio geográfico, os requisitos legais exigidos pelas legislações nacionais e as possibilidades de utilização (exploração) desses institutos requerem formas de regulação distintas, sob pena de não serem atendidas as peculiaridades e necessidades inerentes à proteção efetiva dos conhecimentos tradicionais.

\section{REFERÊNCIAS}

BRASIL. Lei n. 9.279, de 14 de maio de 1996. Regula direitos e obrigações relativos à propriedade industrial. Disponível em: <http://www.planalto.gov.br/ccivil_03/leis/L9279.htm>. Acesso em: 15 jan. 2015.

. Lei $\mathrm{n}^{\mathrm{o}} 13.123$, de 20 de maio de 2015. Regulamenta o inciso II do $\S 1$ o e o $\S$ 4o do art. 225 da Constituição Federal, o Artigo 1, a alínea j do Artigo 8, a alínea c do Artigo 10, o Artigo 15 e os $\S \S 3$ o e 4o do Artigo 16 da Convenção sobre Diversidade Biológica, promulgada pelo Decreto no 2.519, de 16 de março de 1998; dispõe sobre o acesso ao patrimônio genético, sobre a proteção e o acesso ao conhecimento tradicional associado e sobre a repartição de benefícios para conservação e uso sustentável da biodiversidade; revoga a Medida Provisória no 2.186-16, de 23 de agosto de 2001; e dá outras providências. Disponível em: <http://www.planalto.gov.br/ccivil_03/_Ato2015-2018/2015/Lei/L13123.htm>.Acesso em ago. 2015.

DIEGUES, Antonio Carlos Sant'Ana; ARRUDA, Rinaldo S.V.(Orgs). Saberes Tradicionais e Biodiversidade no Brasil. Programa Nacional de Conservação da Biodiversidade. Brasília: Ministério do Meio Ambiente-MMA, 2001.

INPI. Instituto Nacional da Propriedade Industrial. Instrução Normativa n. 25, de 21 de agosto de 2013. 2013. Estabelece as condições para o registro das indicações geográficas. Disponível em:<http://www.inpi.gov.br/images/docs/instrucao_normativa_25_indicacoes_geograficas[2]. pdf $>$. Acesso em: 15 jan. 2015.

FAVERO, Klenize Chagas. As Indicações Ge ográfic as c o m o instrumento de Proteção Jurídica Internacional do Conhecimento Tradicional: harmonizando propostas de OMC, ONU e OMPI. Florianópolis, 2010. p. 109. Dissertação de Mestrado. Programa de PósGraduação em Direito da Universidade Federal de Santa Catarina, Mestrado em Direito..

KARAM, Fabio Hungaro. Conhecimentos tradicionais, propriedade intelectual e política externa brasileira. Campinas, 2008. 192p. Dissertação de Mestrado. Programa de Pós 
Graduação em Direito da Universidade Estadual de Campinas, Instituto de Filosofia e Ciências Humanas.

KIHWELO, Paul Faustin. Indigenous Knowledge: What is it? How and why do we protect it?, In: Journal of World Intellectual Property, v.8, n.3, p.345-359, 2005.

LEUZINGER, Márcia Dieguez. Populações tradicionais e conhecimentos associados aos recursos genéticos: conceitos, características e peculiaridade. In: KISHI, Sandra Akemi Shimada, KLEBA, John Bernhard (Orgs). Dilemas do acesso à biodiversidade e aos conhecimentos tradicionais - direito, política e sociedade. Belo Horizonte: Editora Fórum, 2009.

LOCATELLI, Liliana. Indicações geográficas: a proteção jurídica sob a perspectiva econômica. Curitiba: Juruá, 2007.

MULLER, Manuel Ruiz. La Protección Jurídica de losConocimientosTradicionales: Algunos Avances Políticos y Normativos em América Latina, UICN, BMZ, SPDA, Lima

- Perú, 2006. Disponível em: 〈http://www.sur.iucn.org/publicaciones/lista_documentos.cfm> . Acesso em: nov.2014.

RODRIGUES JUNIOR, Edson Beas. Tutela Jurídica dos Recursos da Biodiversidade, dos Conhecimentos tradicionais e do Folclore. Rio de Janeiro: Elsevir, 2010.

RODRIGUEZ, José Rodrigo. Propriedade intelectual e conhecimentos tradicionais: avaliação crítica da disciplina jurídica brasileira. Relatório de Pesquisa apresentado ao Ministério da Justiça/ PNUD, no projeto "Pensando o Direito", Referência PRODOC BRA 07/004. São Paulo, 2011. Disponível em: <https://drive.google.com/drive/\#recent>. Acesso em: 20 ago. 2014.

SANTILLI, Juliana. Novos Direitos e Socioambientalismo: proteção jurídica à diversidade biológica e cultural. São Paulo: Fundação Petrópolis, 2005.

SCDB. Secretariat of the Convention on Biological Diversity. Disponível em:<http://www.cbd.int/secretariat/>. Acesso em 06 jan. 2015.

SOARES, Ines Virginia Prado. Direito ao (do) Patrimônio Cultural Brasileiro. Belo Horizonte: Forum, 2009.

TEIXEIRA MAZAUDOX, Ana Rachel. Proteção jurídica dos conhecimentos tradicionais associados, questões essenciais em matéria de propriedade intelectual. In: BENJAMIN, Antonio Hermans (Org.). Direitos humanos e meio ambiente. São Paulo: Imprensa Oficial do Estado de São Paulo, 2006. 
UNESCO. Convenção para Salvaguarda do Patrimônio Cultural Imaterial. 2003. Disponível em<http://www.unesco.org/culture/ich/doc/src/00009-PT-Brazil-PDF.pdf > .Acesso em: ago. 2014.

ZANIRATO, Silvia Helena; RIBEIRO, Wagner Costa. Conhecimento tradicional e propriedade intelectual nas organizações multilaterais. In: Revista Ambiente e Sociedade. Campinas, v.10, n.1, p.39-55, jan./jun. 2007. Disponível em: <http://www.scielo.br/pdf/asoc/v10n1/v10n1a04.pdf>. Acesso em 20 ago. 2014.

WIPO. World Intellectual Property Organization Composite study on the protection of Traditional Knowledge.Document prepared by theSecretariat.WIPO/GRTKF/IC/5/8, Genova, abril 2003. Disponível em: http://www.wipo.int/edocs/mdocs/tk/en/wipo_grtkf_ic_8/wipo_grtkf_ic_8_5.pdf >. Acesso em: 06 jun. 2014

. Revised provisions for the protection of traditional knowledge, 2010. Disponível em <http://www.wipo.int/edocs/mdocs/tk/en/wipo_grtkf_ic_8/wipo_grtkf_ic_8_5.pdf>.Acesso em 10 jun. 2015.

. Traditional Knowledge. Disponível em: < http://www.wipo.int/tk/en/>. Acesso em 20 ago. 2014.

WTO. World Trade Organization. Trade Related aspects of Intellectual Property Rrights. TRIPS. Disponível em:<https://www.wto.org/spanish/docs_s/legal_s/27-trips.pdf $>$.Acesso em: 06 jan. 2015.

Declaracion de Doha. 2001. Disponível

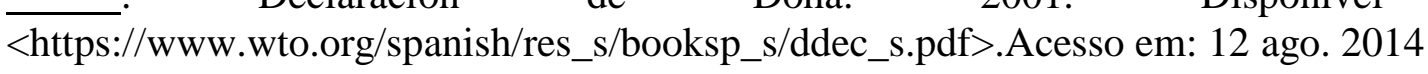

